\title{
Intention to consent to living organ donation: an exploratory study
}

Christina Browne B.A. and Deirdre M. Desmond PhD

Department of Psychology, John Hume Building, National University of Ireland Maynooth, Maynooth, Co. Kildare, Ireland

*Correspondence \& Requests for Reprints:

Dr. Deirdre Desmond, Department of Psychology, John Hume Building, National University of Ireland Maynooth, Maynooth, Co. Kildare,

$$
\text { E-mail: Deirdre.Desmond@nuim.ie }
$$

Telephone: 353-1-708 6479 Fax: 353-1-708 4767 


\begin{abstract}
Living organ donation, i.e. the removal and transplantation of whole organs or segments of organs that a volunteering donor can live without, has been proposed as an effective and sustainable source of transplantable organs to mitigate the deficit in supply from the traditional cadaveric donor pool. In 2006 the Irish government deemed the development of a national Living Transplant Programme a service priority. The current study aimed to investigate the efficacy of the Theory of Planned Behaviour (TPB) in the context of living organ donation intentions in an Irish sample. One hundred and thirty five undergraduate students (75 females, 60 males; mean age 20.6 years, SD 3.76) completed a self-report questionnaire assessing TPB variables whilst imagining themselves in a potential living liver donation scenario. In general, attitudes toward living donation were favorable. TPB components explained $44.8 \%$ of the variance in intentions. Attitude toward living donation emerged as the strongest predictor of intention. Self-reported levels of knowledge regarding living donation were generally poor. In light of recent EU Communications proposing the expansion of the use of living donors greater understanding of the determinants, psychological implications and ethical considerations in living donation decisions is necessary.
\end{abstract}




\section{Introduction}

While the demand for organ transplants continues to grow the number of transplantable organs from the cadaveric donor pool remains relatively static (Samstein \& Emond, 2001). Living organ donation, i.e. removal and transplantation of organs, or segments thereof, that a donor can live without, has been proposed as an effective alternative source of transplantable organs. In fact, transplants performed from living donors have advantages including increased viability of donor organs, improved survival and reduced waiting times (Cecka, 1996). Nonetheless, ethical dilemmas arise relating to postoperative donor morbidity and mortality (Frati, 2005).

At European level, significant increases in living donation have occurred in recent years; living donation represents $17 \%$ of kidney donation activity and $5 \%$ of liver transplantation (European Commission, 2007). In Ireland in 2005-2006, just three of 129 kidney transplants were living donor transplants (Statistics and Audit Directorate UK Transplant, 2006). In 2006, however, the Irish government deemed development of a Living Transplant Programme a service priority. Such development is set against the backdrop of a recent European Commission Communication (European Commission, 2007), which proposes expansion of living donation to increase organ availability. Establishment of this national programme poses ethical, legal, social and psychological questions. An Irish Council for Bioethics (2005) poll revealed that although $81 \%(405 / 500)$ of respondents "slightly" or "stongly" agreed that "living related donation should be promoted in Ireland", about half also agreed that its promotion could put undue pressure on one sibling to donate to another. 
Results of the aforementioned study notwithstanding, little is known about attitudes to living donation in the Irish context. The current study investigated the efficacy of the Theory of Planned Behaviour (TPB) in the context of living organ donation intentions. According to the TPB, performance of a particular behaviour is predicted by the intention to perform the behaviour which in turn is a function of attitude, subjective norm and perceived behavioural control (Ajzen, 1991). Thus individuals are likely to intend to donate organs if they believe the behaviour will lead to valued outcomes, that significant others think they should carry out the behaviour and that they have the necessary resources or opportunities to perform the behaviour.

\section{Method}

\section{Participants and Procedure}

A convenience sample of undergraduate students from a small Irish University completed self-report questionnaires. Participation was voluntary and was not incentivised. Of the 180 questionnaires distributed, 135 were returned (60 males, 75 females; mean age 20.6 years $(\mathrm{SD}=3.76)$; response rate $75 \%)$.

\section{Materials}

The questionnaire introduced a scenario describing a potential living donation situation. Participants had to imagine themselves as a donation candidate for a close family member diagnosed with liver failure. In the scenario there is a long waiting list and the patient is not certain of receiving a transplant. Imagining themselves in the scenario, participants completed questions assessing TPB components developed following the Ajzen and Fishbein framework (Ajzen \& Fishbein, 1980) and based on 
previous literature. Plausibility of the scenario was assessed using a single item rated on a four-point scale: 'very plausible' to 'very implausible'.

Intention was measured using three items addressing the strength of the subject's intention to act as a living donor in the proposed scenario. For example, "I intend to donate part of my liver in this situation;" respondents indicated their response on a scale ranging from very unlikely to very likely. The mean value of the items was used in the analyses. Internal consistency, as measured by Cronbach's alpha, was 0.80 . The attitudes measure, based on nine semantic differentials (e.g., good or bad; pleasant or unpleasant), assessed subjects' positive or negative evaluations of the donation behavior. Positive and negative endpoints were counterbalanced to counteract possible response sets. Items were averaged to obtain the scale score $(\alpha=0.76)$.

Subjective norms were measured by four questions assessing the respondent's evaluation of referents' opinions regarding his/her behavior in the situation described. For example, "Most people important to me would be disappointed in me if I did not donate part of my liver: extremely unlikely to extremely likely." The average of the four items was used in the analyses $(\alpha=0.74)$. Five items were used to measure perceived behavioural control in the context of the scenario described. For example, "I have complete control over donating part of my liver: strongly agree to strongly disagree." Internal consistency for this scale was 0.71 .

The questionnaire concluded with questions addressing willingness to receive a living donation, attitude toward posthumous donation and items regarding knowledge of and support for living donation programs. Answers were measured on five-point scales. 


\section{Data analyses}

Intention was regressed on attitude, subjective norm and perceived behavioural control using standard multiple regression Calculations were computed with SPSS, Version 12.0.1.

\section{Results}

Intentions to donate organs posthumously were generally favourable; $72.6 \%$ indicated they would consent to cadaveric donation $(13.3 \%$ undecided; $14.1 \%$ would not donate). Contrasting with these favourable intentions, just $33.3 \%$ had signed an organ donor card. A clear majority (81\%) indicated they would be "likely" or "very likely" to accept a living donation if they experienced liver failure; $(12 \%$ undecided, while fewer than $8 \%$ were "unlikely" or "very unlikely" to accept).

Approximately three quarters of respondents (77.8\%) were in favor of the expansion of living donor programs, yet just $20.7 \%$ rated their knowledge of living donation as 'very good' or 'good'. More than half the participants $(56.3 \%)$ felt that living donor programs would 'absolutely' or 'probably' be widely accepted in society; (28.9\% undecided; whereas $14.8 \%$ felt they would 'probably not' find widespread acceptance).

[Insert Table 1 about here]

Ninety five per cent of respondents rated the scenario described as plausible or very plausible. Descriptive data and correlations between the scales used are shown in 
Table 1. Regression of intentions onto attitude, subjective norms and perceived behavioural control accounted for $44.8 \%$ of the variability in intentions $\left(\mathrm{F}_{(3,134)}=\right.$ 35.45, $\mathrm{p}<.001$ ), see Table 2. Stronger intentions to act as living donor were related to positive attitudes to living donation $(\mathrm{p}<0.001)$, perceiving more control over the behaviour $(\mathrm{p}=.003)$ and to a less significant extent perceiving more pressure from salient others $(\mathrm{p}=0.053)$.

[Insert Table 2 about here]

\section{Discussion}

In general, attitudes toward organ donation, both posthumous and living, were positive and most participants supported expansion of a living donor program. Yet the majority indicated they were not knowledgeable about living donation. The low rate of organ donor card ownership coupled with favorable attitudes toward posthumous donation suggests that review of the current system of posthumous donation is warranted. This should take place in the context of an EU Communication (European Commission, 2007) proposing the introduction of an European-wide organ donor card and increased use of living donors. There is no national donor registry in Ireland; while signing a donor card indicates donation intention, legally it's a grey area. In practice, next of kin are responsible for donation decisions. Across Europe next of kin refusals vary from $6 \%$ to $42 \%$ (European Commission, 2007). Campaigns to promote organ donation should focus on encouraging communication of donation intentions to ones' next of kin. 
The current findings support the application of the TPB to understanding intentions to act as a living donor. Attitude, subjective norms and perceived behavioural control accounted for $44.8 \%$ of variance in intentions thus supporting the utility of the TPB in understanding the formation of intentions to engage in various behaviours and comparing favourably to levels of prediction reported elsewhere (Armitage \& Conner, 2001). The relatively weak predictive value of subjective norms is consistent with previous research suggesting that subjective norm is usually the weakest of the three theoretical components (Ajzen, 1991; Godin \& Kok, 1996). In the current research attitude was the dominant predictor of behavioural intention. Both positive and negative messages affect beliefs and attitudes regarding living donation. With the roll-out of a national living donor programme it is imperative that quality and safety are promoted and communicated, and that the complex and sensitive ethical issues in living donation are professionally managed (European Commission, 2007).

While this study provides an interesting first step in understanding readiness for living organ donation in Ireland, limitations of the study should be noted and findings interpreted with caution. In this study respondents reacted to a hypothetical scenario. It is not possible to determine whether the intentions expressed would in fact be implemented if the situation actually applied. Furthermore, the participants represent a specialized subset of the Irish population, undergraduate students, who were recruited from a single institution. Research using larger representative samples is necessary to determine whether these findings generalise to the wider Irish population. In addition, the survey response rate and self-report nature of the design may be a source of bias. 
In conclusion, we observed a high rate of intention to consent to living organ donation in the study sample, coupled with generally positive attitudes toward both posthumous and living donation. As has been reported elsewhere (Siminoff, Gordon, Hewlett, \& Arnold, 2001) largely positive views about posthumous organ donation have not translated into subsequent behavioural commitment in the form of signed organ donor cards. 


\section{Acknowledgements}

The authors would like to thank staff of the Geography and Engineering Departments at NUI Maynooth for their assistance with participant recruitment. 


\section{References}

Ajzen, I. (1991). The theory of planned behaviour. Organizational Behavior and Human Decision Processes, 50(2), 179-211.

Ajzen, I., \& Fishbein, M. (1980). Understanding attitudes and Predicting Social Behaviour. Englewood Cliffs, New Jersey: Prentice Hall.

Armitage, C. J., \& Conner, M. (2001). Efficacy of the theory of planned behaviour: A meta-analytic review. British Journal of Social Psychology, 40, 471-499.

Cecka, J. M. (1996). In sickness and in health--High success rates of kidney transplants between spouses. Transplantation Reviews, 10(4), 216-224.

European Commission. (2007). Communication from the Commission to the European Parliament and Council - Organ Donation and Transplantation: Policy Actions at EU level

Frati, P. (2005). Organ Transplantation From Living Donors, Between Bioethics and the Law. Transplantation Proceedings, 37(6), 2433-2435.

Godin, G., \& Kok, G. (1996). The Theory of Planned Behavior: A Review of Its Applications to Health-Related Behaviors. American Journal of Health Promotion, 11(2), 87-98.

Irish Council for Bioethics. (2005). Public Attitudes Towards Bioethics. Dublin: Irish Council for Bioethics.

Samstein, B., \& Emond, J. (2001). Liver transplants from living related donors. Annual Review of Medicine, 52(1), 147-160.

Siminoff, L. A., Gordon, N., Hewlett, J., \& Arnold, R. M. (2001). Factors Influencing Families' Consent for Donation of Solid Organs for Transplantation. Journal of the American Medical Association, 286(1), 71-77. 
Statistics and Audit Directorate UK Transplant. (2006). Transplant Activity in the Republic of Ireland. Bristol: NHS. 